\title{
LONG-TERM STRUCTURAL HEALTH MONITORING OF THE FORTEZZA FORTRESS: APPLICATION OF DAMAGE DETECTION TECHNIQUES ON EXISTING CRACKS
}

\author{
MYRONAS DRYGIANNAKIS ${ }^{1}$, GEORGIOS VLACHAKIS ${ }^{2 *}$ AND ANASTASIA \\ TZIGOUNAKI ${ }^{3}$ \\ ${ }^{1}$ Freelancer Civil / Structural Engineer \\ Rethymnon - Crete, Greece \\ e-mail: myronasdr@gmail.com \\ ${ }^{2}$ ISISE - University of Minho, Department of Civil Engineering \\ Campus de Azurém, 4800-058, Guimarães, Portugal \\ email: giorgovlachaki@gmail.com, (*corresponding author) \\ ${ }^{3}$ Director of the Ephorate of Antiquities of Rethymno, Hellenic Ministry of Culture and Sports \\ Arkadiou 214, P.C. 74100, Rethymno - Crete, Greece \\ email: atzigounaki@culture.gr
}

Keywords: Masonry Cracks, Diagnosis, STORM-project, Climate Change

\begin{abstract}
Structural Health Monitoring (SHM) consists of an elaborated technique, assisting the assessment of existing structures through the detection of active or sudden damages, as well as the diagnosis of possible causes for them. Within the STORM-project [1], the SHM strategy selected for the assessment of the Venetian fortress of Fortezza in Rethymno, Greece was the continuous crack monitoring of four different existing cracks of the structure, due to their relatively large width, located at the Bastion of St. Paul's, Prophet Elias' and St. Luke's as well as the Episcopal mansion.

Besides the crack displacement measurements, several other environmental quantities were monitored at the weather stations, which are known to have a strong influence on the crack width. Considering the fact that most weather fluctuations have reversible effects on structural integrity, it is of great importance to recognize the environmental and operational variation of the structure, and subsequently identify any separate structural change caused by damage [2], [3]. This was achieved by employing a statistical ARX model (Auto-Regressive model with eXogenous input) [4], calibrated for each case after several months. Once this process was completed it was possible to detect possible active damage on the examined structures and estimate possible causes for them.

The successful application of the methodology at the four monitored cracks provided important information about their state of damage, possible causes and early warnings in case of hazard. Over the evaluated period, it appears that the bastion of Prophet Elias is in stable condition, while the bastion of St. Luke and St. Paul are vulnerable to heavy precipitation. Moreover, the Episcopal mansion showed a destabilization response during the rainfall period, which is possible to result in the activation of an overturning mechanism.
\end{abstract}




\section{INTRODUCTION}

Cultural heritage constructions are critically endangered by natural hazards, while their significance has resulted in serious societal efforts to protect and preserve their integrity [5]. Structural Health Monitoring (SHM) has proven to be a valuable assistance in the diagnosis and control process of heritage structures [6]-[10], presenting promising characteristics and potentials. Important aspects of a SHM application include the planning of type and layout of the sensors, and the employment of a damage detection methodology to process the data and derive meaningful conclusions [11].

The present paper illustrates a case study application of a SHM campaign at the Venetian fortress of Fortezza, the foremost landmark in the city of Rethymno, on the island of Crete. The masonry constructions of the monument are exposed to several natural hazards that could hinder their integrity [12]. More specifically, the area of Rethymno is characterized by high seismicity, as well as environmental conditions, intensified by the climate change. Just to mention, partial collapses of the Rampart of Lando Bastion of Chania Venetian Fortifications, in 26 and 28 February 2017 and in 11 and 14 February 2019, due to great storms that hit Crete in winters 2017 and 2019. Herein, it is attempted to estimate the condition of four cracks located in the Fortezza fortress, taking into account the influence of the environmental conditions.

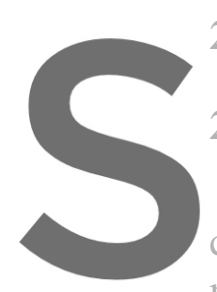

\section{DESCRIPTION}

\subsection{The Fortezza fortress}

In the north-west part consist the foremost natural hill of the city
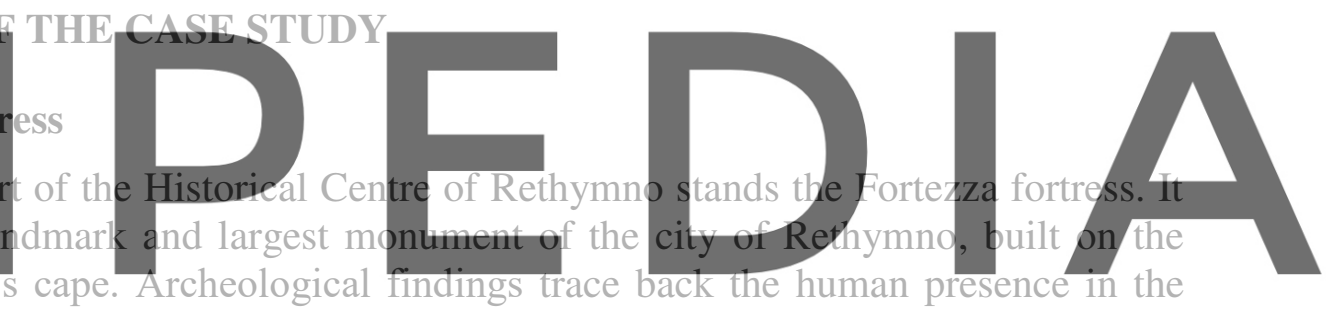
area during Neolithic period, while it has been constantly occupied at least since the

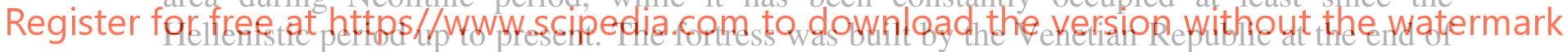

the $16^{\text {th }}$ century and is a representative specimen of the Venetian fortification architecture.

The layout of the fortification is composed by four bastions: two at the south (Prophet Elias and St. Luke) and two at the east (St. Nicolas and St. Paul), while the north and west part of the fortress is next to the sea and has three peaks (the Holy Spirit, the St. Ioustine and the St. Sozon). The total length of the fortification walls counts approximately $1370 \mathrm{~m}$, and their height varies from $6 \mathrm{~m}$ to $13 \mathrm{~m}$.

Despite the fact that the fortress used to enclose many buildings, the vast majority have been destroyed, and only a few there still exist, such as the mosque of Sultan Ibrahim Han, the armory, the Episcopal mansion, the Rector's house, the Chancellor's house etc. Nevertheless, those constructions reflect the different historical phases of the fortress and nowadays host many exhibitions, concerts and cultural events.

\subsection{Structural health monitoring campaign}

In the last decades, the Ephorate of Antiquities of Rethymno (EFARETH) has given a huge effort to protect the monument by carrying out restoration works. As part of this effort, the fortress has been selected and included in the STORM project, with the aim to assist 
EFARETH in assessing and managing risks associated with natural hazards. More specifically, the local partners of the project EFARETH and the Geophysical-Satellite Remote Sensing and Archaeoenvironment Lab of the Institute for Mediterranean Studies - Foundation for Research and Technology, in collaboration with the European partners, conducted hazard studies [12], non-destructive investigation works [13] and developed a methodology and associated supporting tools for early warning and decision making for risk mitigation [1].

Among the works of the STORM project, four cracks have been chosen to be monitored in a long-term basis, due to their relatively large width and their structural significance. The positions of the cracks monitored are displayed in Figure 1 and are located on the fortress' walls at the bastion of Prophet Elias, St. Luke, St. Paul and the west part of the north façade of the Episcopal mansion. The crack at the bastion of Prophet Elias is located at the intruding connection of the bastion with the rest of the wall and propagates vertically. Concerning the crack at St. Luke's bastion, it appears to start from the parapetto and extends downwards to an area reconstructed by the Ottoman's in the late $17^{\text {th }}$ cent. St. Paul bastion's crack appears at the east part of the bastion's corner and expands vertically down to the ground. Finally, the monitored crack at the Episcopal mansion crosses the vault in the longitudinal direction of the west portion of the building aggregate and propagates vertically both at the north and south façades. In each location, a rectilinear displacement transducer (LVDT) has been installed in order to measure the relative displacement movement of the cracks. A sampling period of four hours was chosen as adequate of replicating the daily fluctuation, after an initial test of one

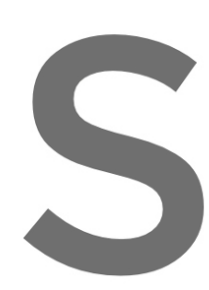
hour sampling.

b)

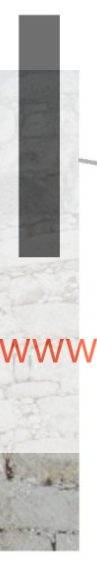

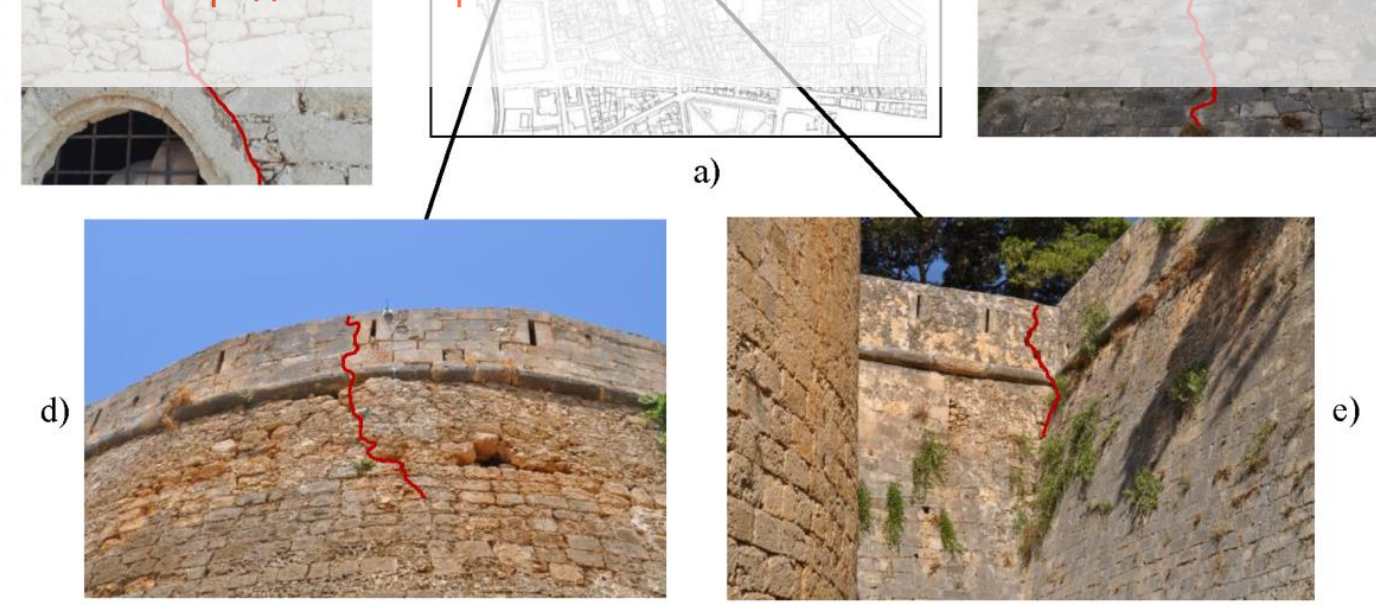
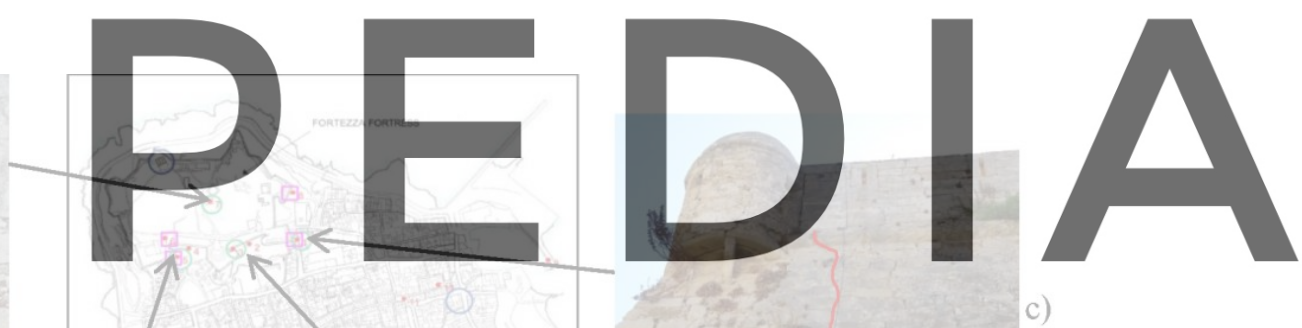

c)

Register for free at https//www.scipedia.com to download the version without the watermark

Figure 1: a) Map of the historical center of Rethymno and the Fortezza fortress; including the locations of: b) the Episcopal mansión, c) the bastion of St. Paul, d) the bastion of St. Luke, and e) the bastion of Prophet Elias. The positions and patterns of the monitored cracks are highlighted. 
It is well known that environmental conditions affect the structural state of constructions [2], [3], [14], especially in case of cracks [15]-[17]. Therefore, besides the crack displacement measurement, several other environmental quantities were monitored by a weather station installed on the fortress. These included external temperature, relative humidity, precipitation and wind speed and direction. Moreover, the board temperature of each crackmeter was also measured.

The present paper presents results of each crack for the periods shown in Table 1. For the case of St. Paul only a few months of measurements were available due to technical issues.

Table 1: Periods of available measurements of the crack monitoring campaign

\begin{tabular}{ll}
\hline Bastion of Prophet Elias & $24 / 05 / 2018-10 / 10 / 2019$ \\
\hline Bastion of St. Luke & $31 / 05 / 2018-10 / 10 / 2019$ \\
\hline Bastion of St. Paul & $13 / 07 / 2017-06 / 02 / 2018$ \\
\hline Episcopal mansion & $24 / 05 / 2018-10 / 10 / 2019$ \\
\hline
\end{tabular}

\section{DAMAGE DETECTION METHODOLOGY}

\subsection{Strategy of the adopted methodology}

The main task of SHM is to identify the presence or not of an active damage process on the structure, by employing a damage detection methodology. The main challenge of such a methodology is to be able to describe the environmental and operational variation of the structure, and subsequert of major importance, parameters induced by damage. In this study, model) has been employed, previously proposed and used by

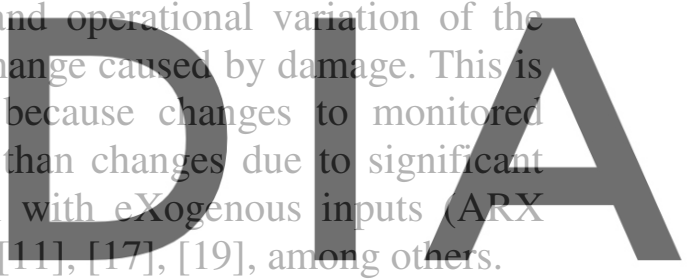

Initially, a calibration phase is required to create the statistical ARX model, which

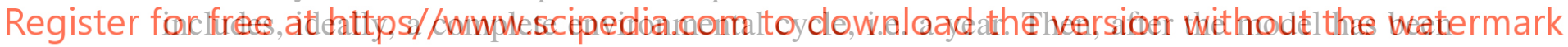
created, the prediction phase starts, during which the model's prediction is compared with the actual measurements. This comparison, which can be done by a residual analysis, is the key point of the methodology, since it should provide a removal of the effect of the environmental conditions on the signal. In other words, if the real measurements diverge significantly from the predicted values, then another separate process is acting on the structure, which was not taken into account by the statistical model. This indicates a change of the response which might be irreversible (active damage).

\subsection{Brief description of the ARX model}

The basic advantage of the statistical ARX model is its ability to relate the present outputs to past inputs and outputs. This feature, in contrast with static linear or non-linear regression models, makes it ideal for representing monitored parameters that depend on the rate of change or trend of an environmental parameter. This is a key aspect for huge and complex structures, which are characterized by e.g. thermal inertia, such as the Fortezza fortress examined herein.

The mathematical expression of the multivariable ARX model with $n$ inputs $x$ and one 
output $y$ is presented by:

$$
\hat{y}_{k}+a_{1} y_{k-1}+\cdots+a_{n a} y_{k-n a}=b_{1} x_{k-n k}^{e n v}+b_{2} x_{k-n k-1}^{e n v}+\cdots+b_{n b} x_{k-n k-n b+1}^{e n v}+e_{k}
$$

Where $y_{k}$ is the monitored response (actual measurement) in the instant $k, \hat{y}_{k}$ is the estimated response, $x^{e n v}$ is the input environmental parameter (e.g. the temperature), $a_{i}$ and $b_{i}$ are coefficients for the autoregressive and exogenous part, respectively, $n_{a}$ is the autoregressive order, $n_{b}$ the exogenous order, $n_{k}$ is the number of delays from input to output and $e_{k}=y_{k}-\hat{y}_{k}$ is the unknown residual that can be assumed Gaussian. The coefficients of the polynomials $a_{i}$ and $b_{i}$ can be estimated using the simple linear least square method. In this work, the SISO form of the ARX model is employed; yet it could be expanded to include multiple input variables i.e. having a MISO form [18]. In that case, eq. (1) is still valid but $x^{e n v}$ is a column vector, the $b_{i}$ coefficients are row vectors and a distinct order $n_{b}$ and $n_{k}$ characterizes each input variable

The choice of the appropriate AR model order is done with the assistance of the quality criteria proposed by [18]-[20]. These criteria include: a) the value of the loss function $V, b$ ) the Akaike's Final Prediction Error FPE, c) the coefficient of determination $R^{2}$, and d) the autocorrelation function $\lambda_{i}$. Firstly, the loss function is defined as: $V=\frac{1}{N} \sum_{k=1}^{N} e_{k}^{2}$, where $e_{k}$ is the residual error, and its value represents a finer model as it tends to zero. Secondly, the Final Prediction Error is defined as: $=V \frac{1+d / N}{1-d / N}$, where $V$ is the loss function and $d$ is the number of

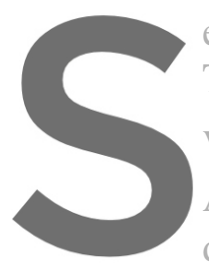
estimated parameters The coefficient of deter values of the model

A higher value of $R^{2}$ defined as $\lambda_{\mathrm{i}}=\frac{1}{\mathrm{~N}} \sum_{\mathrm{k}=}^{\mathrm{N}}$
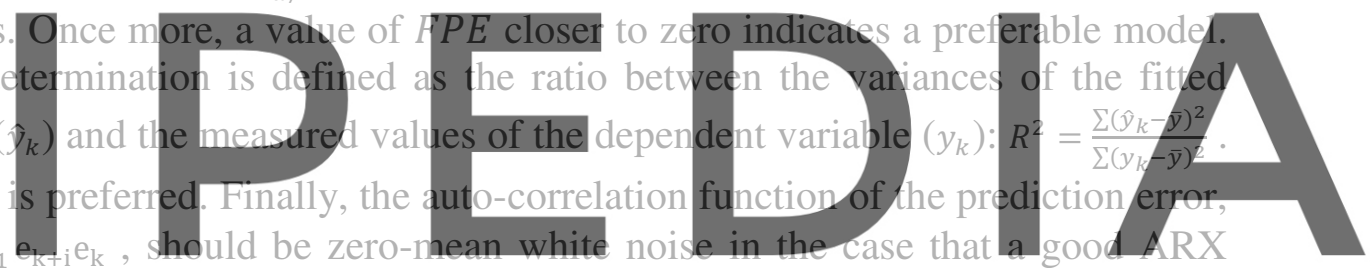
model is obtained.

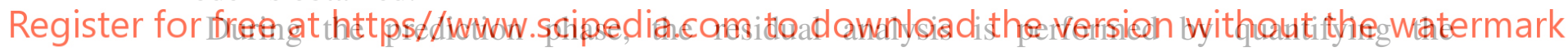
simulation error $e_{k}=y_{k}-\hat{y}_{k}$. Confidence intervals can be established based on the statistics of the prediction, in order to judge whether the simulation error is statistically significant or not. If $\hat{y}$ is the predicted output and $\hat{\sigma}_{y}$ the estimated standard deviation on a new observation, the $(100-a) \%$ confidence interval on $\hat{y}$ is given by:

$$
\left[\hat{y}-t_{a / 2, v} \hat{\sigma}_{y}, \quad \hat{y}+t_{a / 2, v} \hat{\sigma}_{y}\right]
$$

where the value $t_{a / 2, v}$ is found from a statistical table of the t-Student distribution. The established confidence intervals can be considered as warning thresholds for possible damage detection in real time, and thus provide an instant alert in case of sudden-onset hazard.

The workflow of the aforementioned methodology is presented in the following Table 2.

Table 2: Workflow of damage detection methodology

1. Read and filter data at specified sampling period

2. Calculate basic statistical characteristics of data

3. Decide environmental parameters to consider in the ARX model 


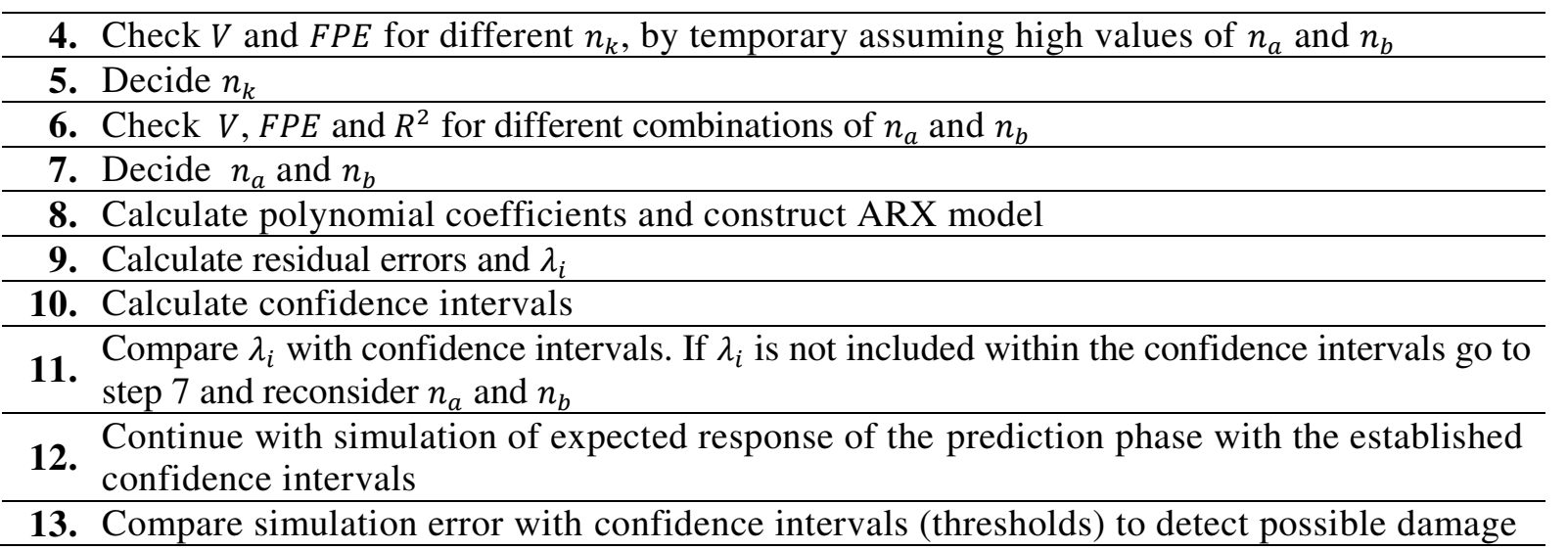

\section{RESULTS AND DISCUSSION}

The results after the application of the aforementioned methodology are presented in Figure 2 - Figure 5. More specifically, Figure 2 shows the evolution in time of the four monitored cracks and the corresponding board temperatures. Figure 3 shows the correlation of the same measurements, while highlighting the time evolution through a color scale (blue to yellow). Figure 4 demonstrates the fitting achieved using the proposed ARX model for all the crackmeters, also indicating the date of calibration. Finally, Figure 5 illustrates the results of the residual analyses of the actual measurements and the statistical model, including the derived thresholds. In th bastion of St. Paul due tro In all cases, both examining the correlation environmental paramete
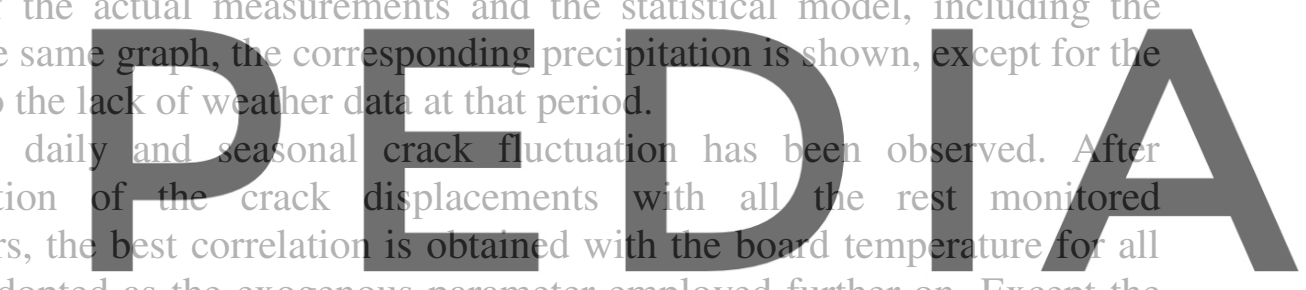
cases, and therefore is adopted as the exogenous parameter employed further on. Except the

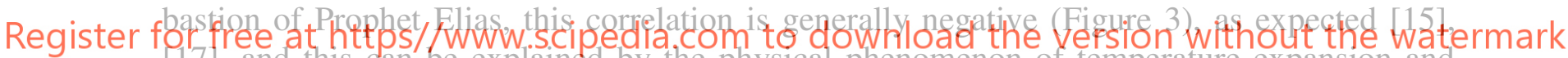
[17], and this can be explained by the physical phenomenon of temperature expansion and contraction: as the temperature rises, the stones at the two sides of the crack expand causing a crack closure, and vice-versa for contraction.

In the case of the bastion of Prophet Elias, a negative correlation is observed only in a daily basis, while when considering the complete seasonal response, a positive correlation is obtained. An explanation to this phenomenological paradox could resort to any or a combination of the following: a) the highly statically indeterminate nature of the structure, b) the complex boundary conditions affecting the fortress walls, or even c) the closely presence of other cracks. It is interesting to note that this positive correlation is shown in Figure 2a to have a delay of about two months. This is also observed in Figure $3 \mathrm{a}$ by the circular path tracing the response (from blue to yellow), instead of a simple linear. This delay peculiarity indicates that thermal inertia is guiding the global response: probably the thermal inertia of the whole bastion. Nevertheless, a good fit is obtained by the ARX model, while no significant excess of the confidence intervals is shown in Figure 5a, underlining a stable condition of the crack.

The crack at the bastion of St. Luke is characterized by several response peaks at specific dates. Those peaks appear in most cases at low temperatures (Figure 3b), while after a closer 
look at Figure $5 \mathrm{~b}$ it is clear that they coincide with rainfall events. Interestingly, not all rainfall events cause a destabilization. Yet, despite these peaks of relative displacement, the crack opening appears to recover after the specific events, without retaining a residual displacement (Figure 3b). The aforementioned characteristics indicate that this vulnerability is possibly arising by the saturation and in turn expansion of the backfill soil of the fortress wall. This finding is in line with [1], where the presence of water flows and moisture in the filling material was identified using the Electrical Resistivity Tomography (ERT) method.
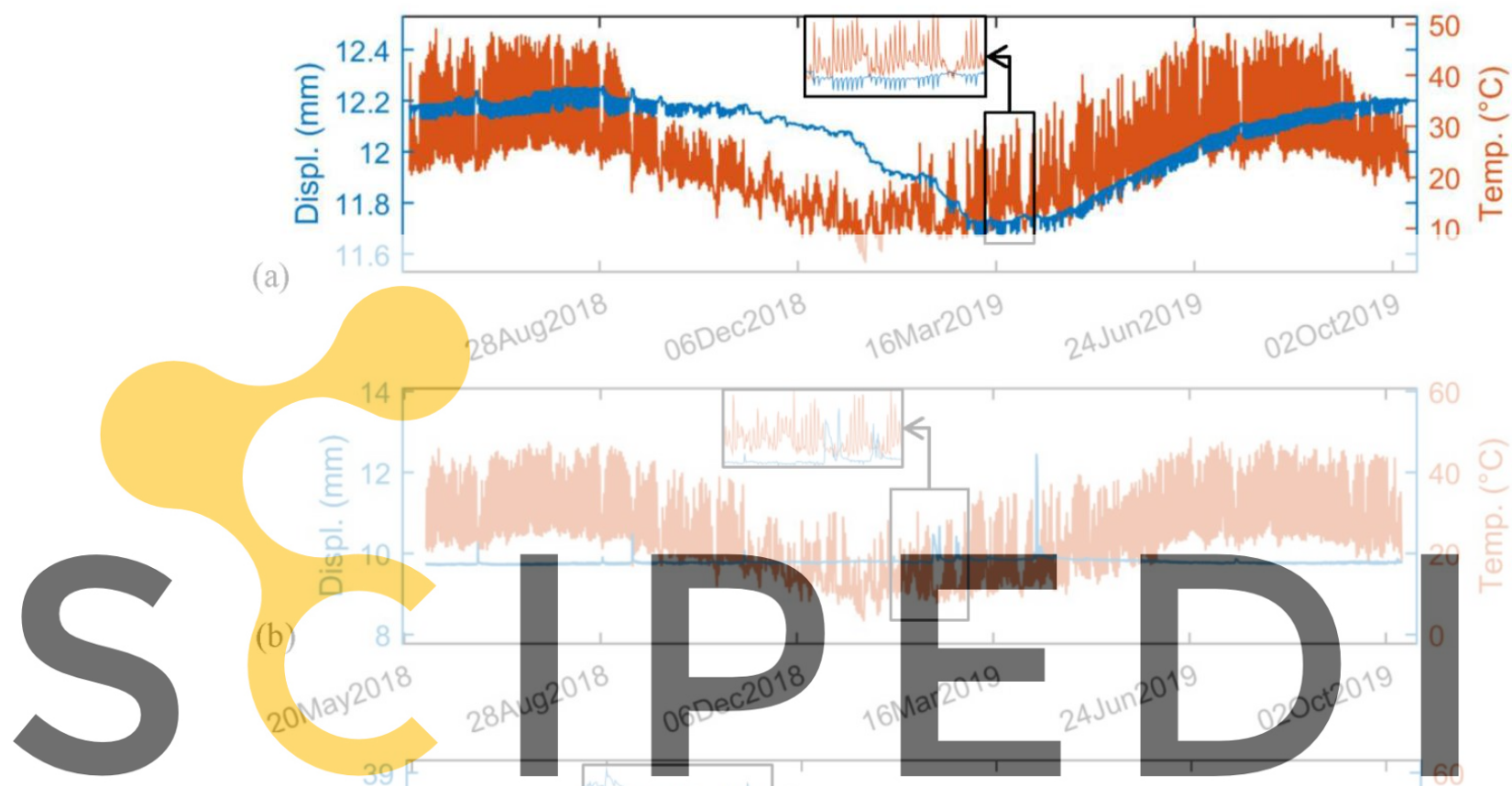

(a)

Register for free at https//www.scipedia.com to download the version without the watermark

(c)
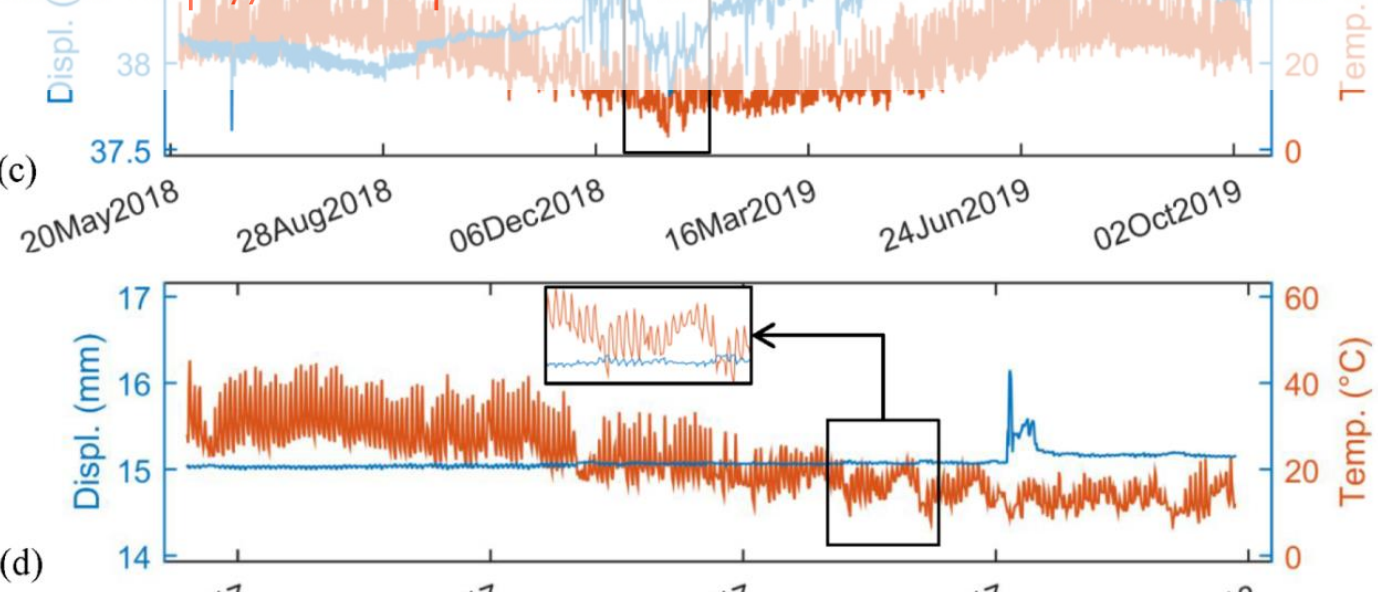
$24 J 412017$
$12 \mathrm{sep}^{2017}$
OINOV 2017
$21 \mathrm{Dec}^{2017} \quad 09 \mathrm{Feb}^{\mathrm{b} 2018}$

Figure 2: Time history of monitored crack displacement and board temperature for: a) the bastion of Prophet Elias, b) the bastion of St. Luke, c) the Episcopal mansión, and d) the bastion of St. Paul 


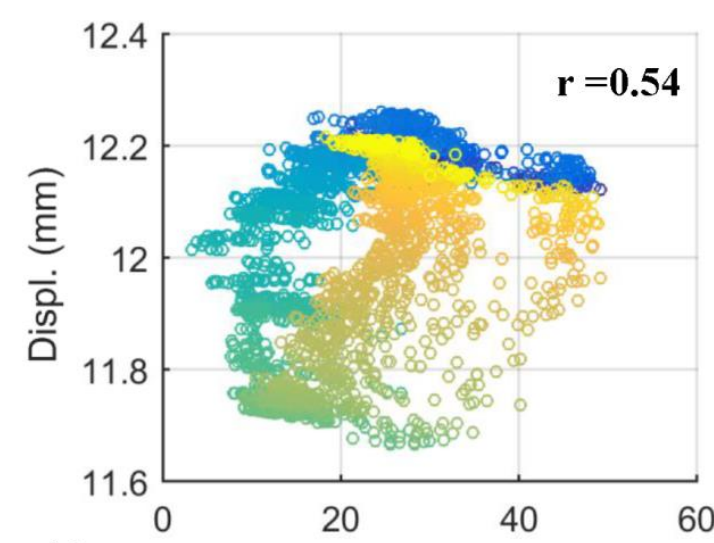

(a)

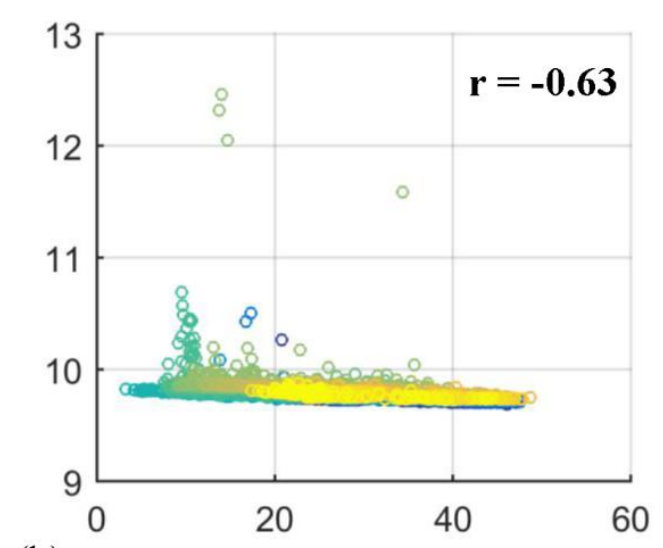

(b)

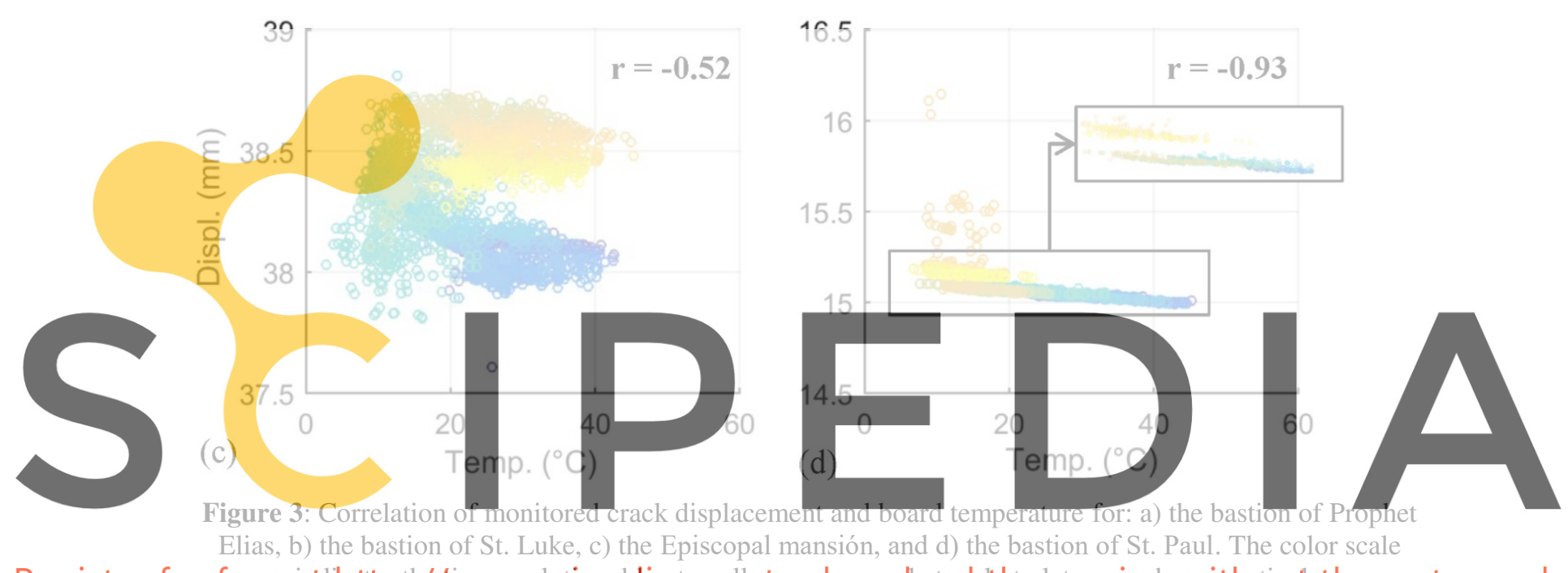

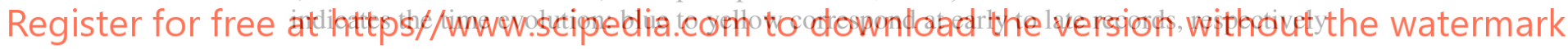

The Episcopal mansion's crack shows an unstable response during the winter (Dec. 2018 April 2019), coinciding with high rainfalls (Figure 5c). More specifically, high variations of the crack opening are observed, when compared with other periods of the year. After this period, the crack appears to be stable again, although around a new equilibrium position, with a gain of around $0.5 \mathrm{~mm}$. This is clearly shown in Figure $3 \mathrm{c}$, where the blue points represent the equilibrium position before the winter, the green points the high fluctuation of the winter and the yellow points the new equilibrium position right after, having an offset from the initial. In contrast with the instabilities of the bastions of St. Luke and Paul where only a crack widening is observed, the variation in this case appear both positive and negative, as this is not a retaining structure. Therefore, a possible cause could be a foundation soil settlement due to intense rainfalls, or an intense evolution of the deterioration process due to the harsh weather conditions.

As already mentioned, for the bastion of St. Paul only a few measurements are available, and therefore the following outcomes might not be fully representative of the complete response of the crack. A normal response is observed until the end of December 2017. Then, the crack shows a destabilization for several days, and thereafter it stabilizes again but with a 


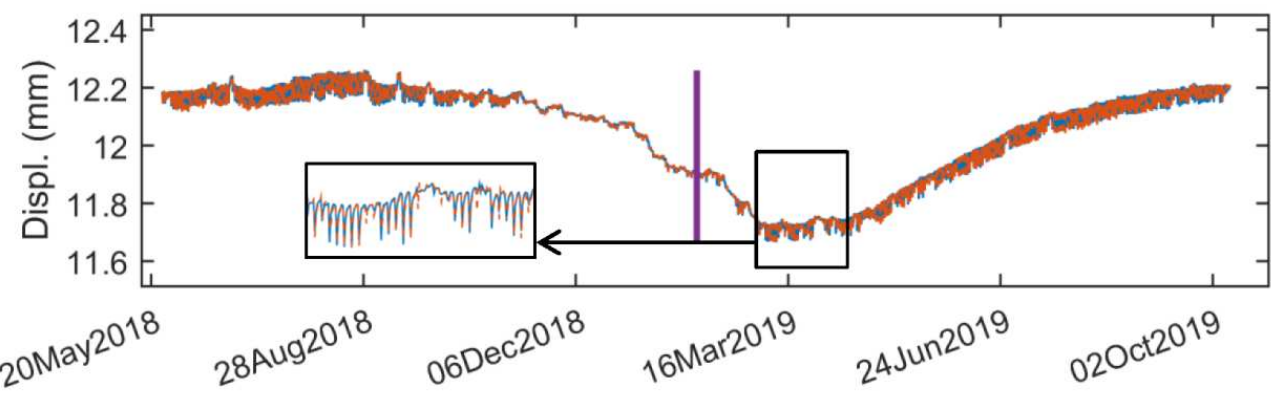

(a)
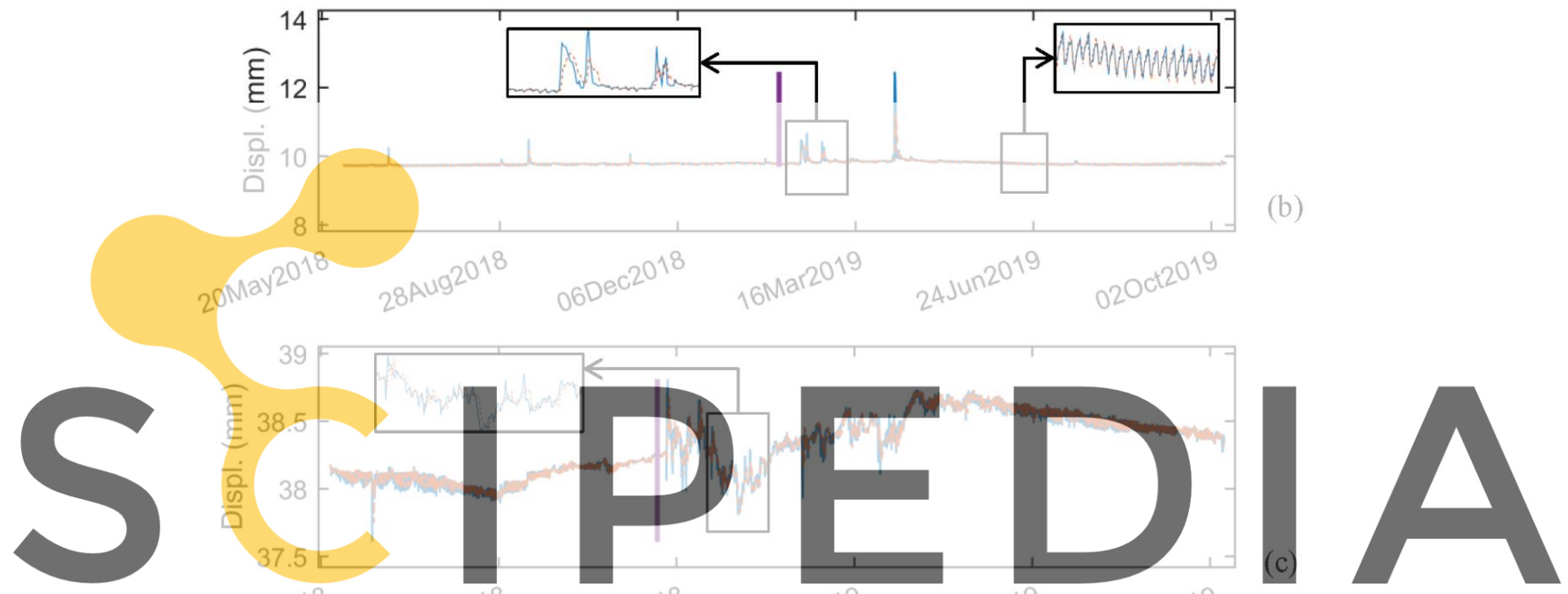

Register for free at htt ps//www.scipedia.com to download the version without the watermark

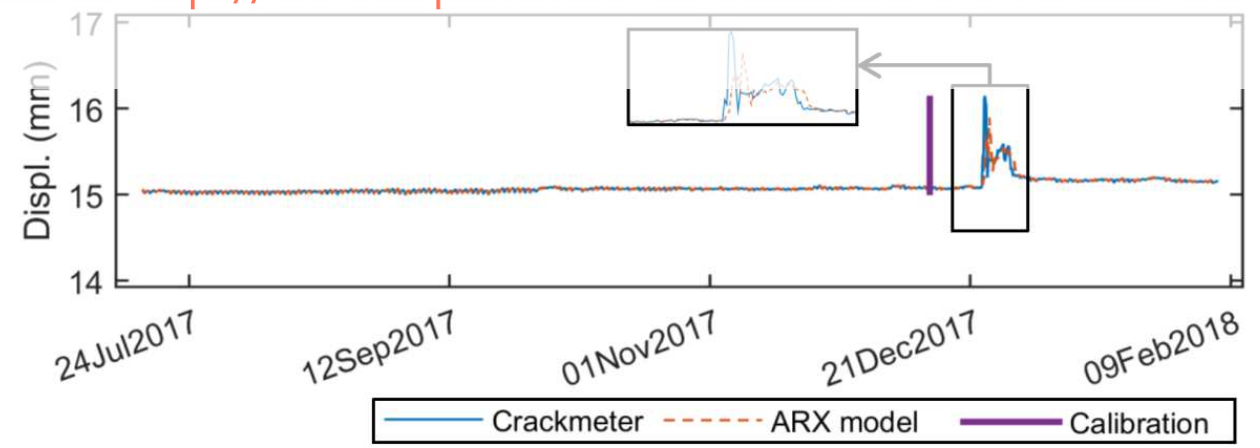

(d)

Figure 4: Time history of monitored crack displacement and the corresponding prediction of the ARX model for: a) the bastion of Prophet Elias, b) the bastion of St. Luke, c) the Episcopal mansión, and d) the bastion of St. Paul

retained displacement. This is clearly illustrated in Figure 3d, where an offset appears between the blue and yellow points, yet with a small gain of around $0.1 \mathrm{~mm}$. In the same figure it can also be appreciated that those peaks always appear during low temperatures, as possible cause a rainfall event. Moreover, similarly with St. Luke, [1] have pointed out that 
the filling material retains moisture due to water flow. Although precipitation measurements are not available for this period to derive a quantitative correlation, by looking the local daily weather data available online by the National Observatory of Athens, rainfall events occurred the same days of destabilization.
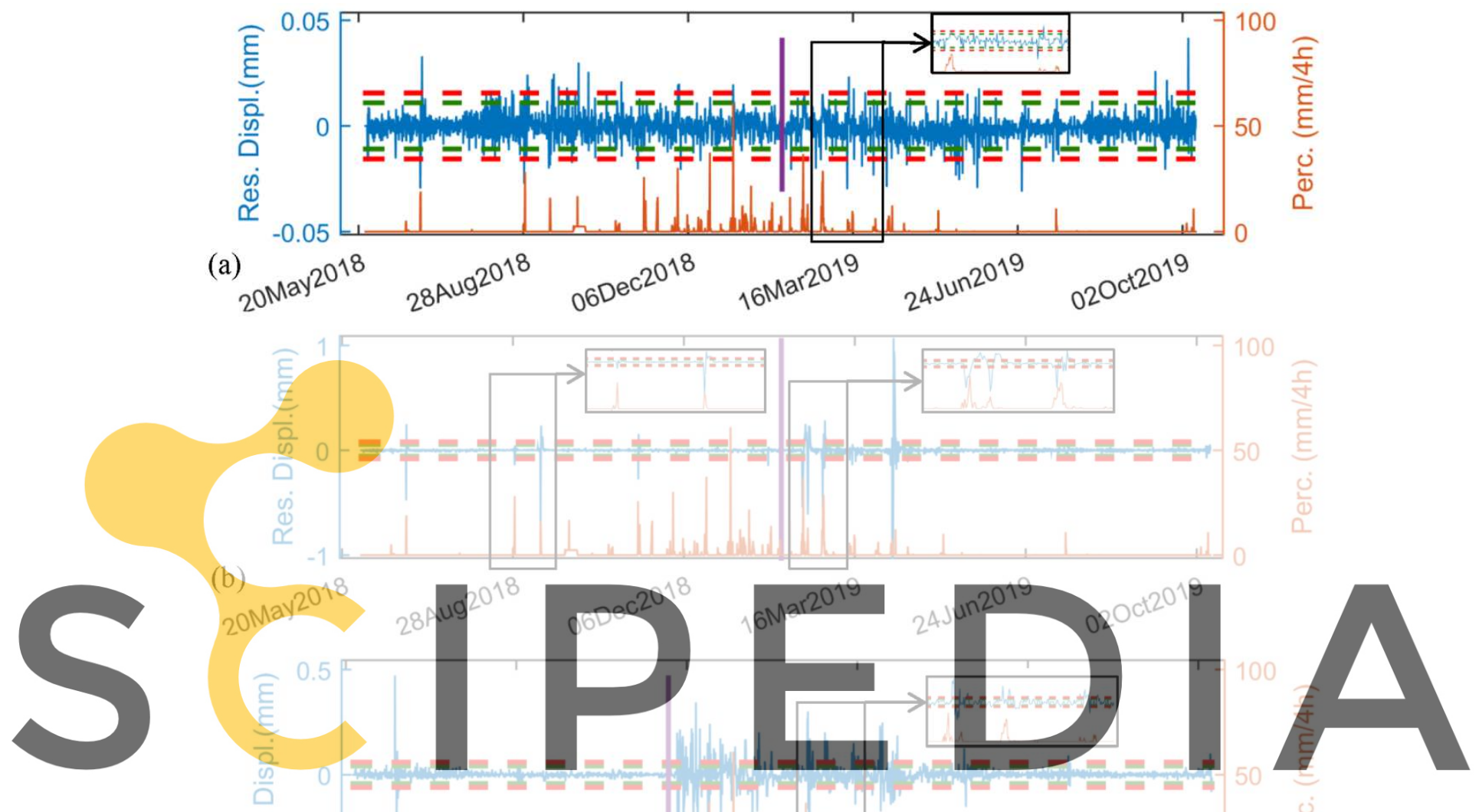

Register for freewat https//www.scipedia.com to download the version without the watermark
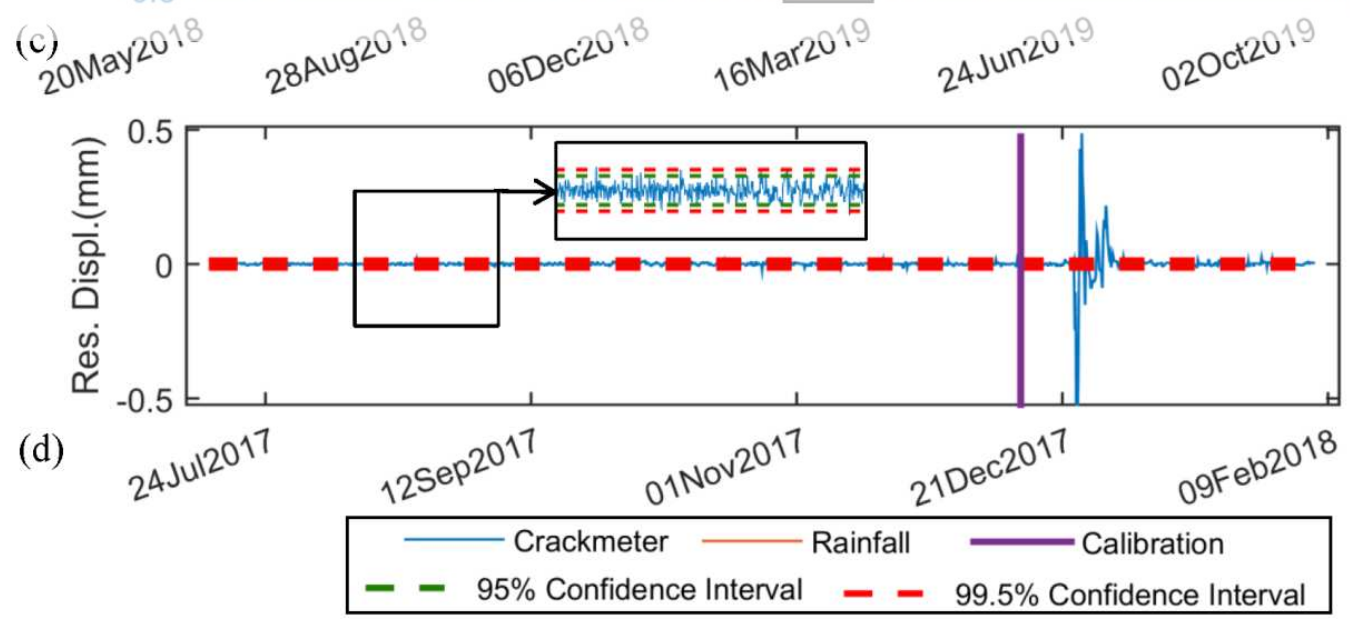

Figure 5: Time history of the residual analyses of the monitored crack displacement and the corresponding prediction of the ARX model, including percipitation and confidence interval thresholds for: a) the bastion of Prophet Elias, b) the bastion of St. Luke, c) the Episcopal mansión, and d) the bastion of St. Paul. 


\section{CONCLUSIONS}

This study presents the application of a long-term SHM campaign on four cracks of the Fortezza fortress in the city of Rethymno, in Greece. Being part of the STORM project, the aim of the application is to develop an appropriate methodology and associated supporting tools and services to assess and manage risks associated with natural hazards.

A weather station was also installed, in order to assess the influence that the environmental conditions have on the cracks. A statistical ARX model is employed to describe the cyclic environmental operational variation of the cracks, and therefore detect any separate acting damage on the structure.

The crack at the bastion of Prophet Elias illustrates a stable condition, during the examined period. In the case of St. Luke, the crack shows a widening during rainfalls, yet followed by a full recovery. The Episcopal mansion's crack appears to be unstable during winter and intense rainfalls. An increase of the crack-width is retained after such events, which could compromise its safety. Finally, not enough measurements are yet available in order to conclude with certain about the bastion of St. Paul. However, the present results indicate vulnerability in rainfalls, once more, so EFARETH proceeded to urgent structural stabilization of the bastion's watchtower.

Considering the outcomes of the present work, future developments could attempt to include the influence of precipitation and humidity data in the ARX model. To this end, the MISO form of the model could be employed.

Acknowledgements. This article is based on the STORM (Safeguarding Cultural Heritage through Technical and Organisational Resources Management) Project, funded by the European Union's Horizon 2020 research and innovation program under Grant agreement No. 700191.

\section{REFERENCES}

[1] V. Resta, A. B. Utkin, F. M. Neto, and C. Z. Patrikakis, Cultural Heritage Resilience Against Climate Change and Natural Hazards. Pisa University Press, 2019.

[2] H. Sohn, "Effects of environmental and operational variability on structural health monitoring," Philos. Trans. R. Soc. A Math. Phys. Eng. Sci., vol. 365, no. 1851, pp. 539-560, 2007.

[3] G. Zonno, R. Aguilar, R. Boroschek, and P. B. Lourenço, “Analysis of the long and short-term effects of temperature and humidity on the structural properties of adobe buildings using continuous monitoring," Eng. Struct., vol. 196, no. December 2018, p. 109299, 2019.

[4] C. Modena, F. Lorenzoni, M. Caldon, and F. da Porto, "Structural health monitoring: a tool for managing risks in sub-standard conditions," J. Civ. Struct. Heal. Monit., vol. 6, no. 3, pp. 365-375, 2016.

[5] P. Roca, P. B. Lourenço, and A. Gaetani, Historic Construction and Conservation. New York: Routledge, 2019.

[6] M. G. Masciotta, L. F. Ramos, and P. B. Lourenço, "The importance of structural monitoring as a diagnosis and control tool in the restoration process of heritage structures: A case study in Portugal," J. Cult. Herit., vol. 27, pp. 36-47, 2017. 
[7] A. Dal Cin and S. Russo, "Evaluation of static and dynamic long-term structural monitoring for monumental masonry structure," J. Civ. Struct. Heal. Monit., vol. 9, no. 2, pp. 169-182, 2019.

[8] P. Roca, C. Blasi, and F. Ottoni, "Editorial," Int. J. Archit. Herit., vol. 9, no. 1, p. 1, 2015.

[9] M. G. Masciotta, J. C. A. Roque, L. F. Ramos, and P. B. Lourenço, “A multidisciplinary approach to assess the health state of heritage structures: The case study of the Church of Monastery of Jerónimos in Lisbon," Constr. Build. Mater., vol. 116, pp. 169-187, 2016.

[10] F. Lorenzoni, F. Casarin, C. Modena, M. Caldon, K. Islami, and F. da Porto, "Structural health monitoring of the Roman Arena of Verona, Italy," J. Civ. Struct. Heal. Monit., vol. 3, no. 4, pp. 227-246, 2013.

[11] F. Lorenzoni, F. Casarin, M. Caldon, K. Islami, and C. Modena, "Uncertainty quantification in structural health monitoring: Applications on cultural heritage buildings," Mech. Syst. Signal Process., vol. 66-67, pp. 268-281, 2016.

[12] M. Ravankhah et al., "Integrated Assessment of Natural Hazards, Including Climate Change's Influences, for Cultural Heritage Sites: The Case of the Historic Centre of Rethymno in Greece," Int. J. Disaster Risk Sci., vol. 10, no. 3, pp. 343-361, 2019.

[13] M. Manataki, A. Sarris, D. Oikonomou, K. Simirdanis, G. Strapazzon, and P. T. Fernández, "Contribution of GPR method in monitoring and evaluating the conservation state of Fortezza, Rethymno, Greece," 2018 17th Int. Conf. Gr. Penetrating Radar, GPR 2018, 2018.

[14] F. Ubertini, G. Comanducci, N. Cavalagli, A. Laura Pisello, A. Luigi Materazzi, and F. Cotana, "Environmental effects on natural frequencies of the San Pietro bell tower in Perugia, Italy, and their removal for structural performance assessment," Mech. Syst. Signal Process., vol. 82, pp. 307-322, 2017.

[15] A. Kita, N. Cavalagli, and F. Ubertini, "Temperature effects on static and dynamic behavior of Consoli Palace in Gubbio, Italy," Mech. Syst. Signal Process., vol. 120, pp. 180-202, 2019.

[16] R. Ceravolo, A. De Marinis, M. L. Pecorelli, and L. Zanotti Fragonara, "Monitoring of masonry historical constructions: 10 years of static monitoring of the world's largest oval dome," Struct. Control Heal. Monit., vol. 24, no. 10, pp. 1-11, 2017.

[17] F. Casarin, F. Porto, C. Modena, P. Girardello, and I. Kleidi, "Optical Structural Health Monitoring of the Frescoes in the Conegliano Cathedral, Italy," in SAHC2014 - 9th International Conference on Structural Analysis of Historical Constructions, no. October, F. Pena and M. Chavez, Eds. 2014.

[18] B. Peeters, "System identification and damage detection in civil engineering, $\mathrm{PhD}$ Dissertation," Katholieke Universiteit Leuven, 2000.

[19] L. F. Ramos, "Damage identification on masonry structures based on vibration signatures," PhD Thesis, 2007.

[20] F. Lorenzoni, "Integrated methodologies based on Structural Health Monitoring for the protection of Cutural Heritage buildings. PhD Thesis," University of Trento, 2013. 